\title{
Two-dimensional titanium carbide MXenes as efficient non-noble metal electrocatalysts for oxygen reduction reaction
}

\author{
Han Lin ${ }^{1,3}$, Lisong Chen ${ }^{2^{*}}$, Xiangyu Lu ${ }^{1,3}$, Heliang $\mathrm{Yao}^{1}, \mathrm{Yu} \mathrm{Chen}^{{ }^{*}}$ and Jianlin Shi ${ }^{1,2^{*}}$
}

\begin{abstract}
MXenes, a new family of multifunctional two dimensional (2D) solid crystals integrating high electroconductivity and rich surface chemistries, are promising candidates for electrolysis, which, however, have rarely been reported. Herein, free-standing ultrathin 2D MXene nanosheets were successfully fabricated from bulky and rigid MAX phase ceramics by liquid exfoliation with HF etching (delamination) and TPAOH intercalation (disintegration). The high oxygen reduction reaction (ORR) performance has been obtained, due to the extremely small thickness of the asfabricated $\mathrm{Ti}_{3} \mathrm{C}_{2}$ around $0.5-2.0 \mathrm{~nm}$, equivalent to the dimensions of single-layer or double-layer $\mathrm{Ti}_{3} \mathrm{C}_{2}$ nanosheets in thickness. The ORR performance of the obtained $\mathrm{Ti}_{3} \mathrm{C}_{2}$ MXene-based catalyst exhibits desirable activity and stability in alkaline media. This study demonstrates the potential of earth-abundant 2D MXenes for constructing high-performance and cost-effective electrocatalysts.
\end{abstract}

Keywords: MXene, titanium carbide, electrocatalysis, oxygen reduction reaction

\section{INTRODUCTION}

The advances of cutting-edge technologies, such as metal-air batteries and fuel cells, provide highly potential and sustainable alternative solutions to tackle the increasing severe energy and environmental issues. Highly active and durable electrocatalysts for cathodic oxygen reduction reaction (ORR) are indispensable for the widespread application of fuel cells. The state-of-theart catalysts are mainly based on noble metals such as platinum $(\mathrm{Pt})$, but the high cost, limited resources, and poor durability have significantly hampered the commercialization of the Pt-based fuel cells. On this ground, the research of cost-effective nonprecious metal catalysts (NPMCs) has been a foremost subject of the electrocatalysis. In the past decades, great efforts have been made to develop non-Pt family metals or even metal-free alternatives as ORR catalysts [1,2]. Especially, rapid progress has been achieved on metal-free ORR electrocatalysts, such as mesoporous carbons, heteroatom-doped graphene, and carbon nanotubes (CNTs) [3-10]. Very recently, studies on electrocatalysis of transition metal carbides (MXenes) have attracted increasing attention [11-17]. MXenes, possessing hydrophilic surface with prominent conductivity and stability, can be expected as promising electrocatalysts. In particular, the recently reported research has focused on the MXene composites for electrocatalysis, such as the overlapped $\mathrm{g}-\mathrm{C}_{3} \mathrm{~N}_{4}$ and $\mathrm{Ti}_{3} \mathrm{C}_{2}$ nanosheets composites (TCCN) as a catalyst for oxygen evolution reaction (OER) [13], and MXene-Ag composites for ORR process [17].

Two-dimensional (2D) materials and structures have stimulated great attention during the past decade due to their ultrathin nanostructure and intriguing physiochemical properties [18-24]. Very recently, MXenes, a new family of multifunctional 2D solid crystals including a large class of carbides, nitrides, and carbonitrides with metallic conductivity and hydrophilicity, as well as good mechanical properties, were developed by Gogotsi, Barsoum and their colleagues [25,26]. The chemistry of MXenes led to versatile applications in energy storage [27-32], water purification [33], chemical sensors [34,35],

\footnotetext{
${ }^{1}$ State Key Laboratory of High Performance Ceramics and Superfine Microstructures, Shanghai Institute of Ceramics, Chinese Academy of Sciences, Shanghai 200050, China

${ }^{2}$ Shanghai Key Laboratory of Green Chemistry and Chemical Processes, School of Chemistry and Molecular Engineering, East China Normal University, Shanghai 200062, China

${ }^{3}$ University of Chinese Academy of Sciences, Beijing 100049, China

* Corresponding authors (emails: lschen@chem.ecnu.edu.cn (Chen L); chenyu@mail.sic.ac.cn (Chen Y); jlshi@mail.sic.ac.cn (Shi J))
} 
photo- or electrocatalysis [16], electromagnetic interference shielding [36,37] and biomedical fields [38-41]. To date, the electrochemical process of MXenes also has attracted increasing attention for catalysis. Notably, employing multifunctional 2D MXenes as effective electrocatalysts for oxygen reduction may offer the following advantages: (i) the prominent metallic conductivity of 2D MXene facilitates highly efficient chargecarrier transfer; (ii) the terminal metal site on the surface (e.g., $\mathrm{Ti}, \mathrm{Nb}, \mathrm{V}$ or $\mathrm{Ta}$ ) of $2 \mathrm{D}$ MXenes results in stronger redox reactivity than that of other carbon-based materials; (iii) 2D MXenes have high stability in aqueous media; (iv) hydrophilic surface of 2D MXenes leads to strong interaction with catalytic targets or water molecules.

With the above advantages, MXenes could be employed as an ideal candidate in electrocatalysis. However, to the best of our knowledge, there is no report on exploiting the intrinsic electrocatalytic oxygen reduction performance of $\mathrm{Ti}_{3} \mathrm{C}_{2}$ MXene. In this study, we focus on the newly discovered $2 \mathrm{D}$ titanium carbide $\left(\mathrm{Ti}_{3} \mathrm{C}_{2}\right)$ MXene as non-noble electrochemical catalysts for oxygen reduction. The synthesis and delamination of ultrathin $2 \mathrm{D} \mathrm{Ti}_{3} \mathrm{C}_{2}$ nanosheets were achieved by a liquid exfoliation method combining $\mathrm{HF}$ etching (delamination) and $\mathrm{TPAOH}$ intercalation (disintegration). The thickness distribution of the as-fabricated $\mathrm{Ti}_{3} \mathrm{C}_{2}$ is around $0.5-2.0 \mathrm{~nm}$, which matches well with the dimension of a single-layer or double-layer $\mathrm{Ti}_{3} \mathrm{C}_{2}$ nanosheet in thickness. Electrochemical measurements suggest that the obtained $2 \mathrm{D} \mathrm{Ti}_{3} \mathrm{C}_{2}$ MXene has desirable ORR activity, stability as well as methanol crossover effect. This work presents a modified strategy for the synthesis of ultrathin $2 \mathrm{D} \mathrm{Ti}_{3} \mathrm{C}_{2}$ MXene with high performance towards ORR.

\section{EXPERIMENTAL SECTION}

\section{Fabrication of $\mathrm{Ti}_{3} \mathrm{C}_{2}$ MXene}

The bulk $\mathrm{Ti}_{3} \mathrm{AlC}_{2}$ (MAX phase) was sintered by mixing titanium powder (99.5 wt\% purity; 325 mesh), aluminum powder (99.5 wt\% purity; 325 mesh) and graphite powder (99 wt\% purity; particle size $<48 \mu \mathrm{m}, 300$ mesh), in a 2:1:1 molar ratio. All of these reagents were purchased from Alfa Aesar, Ward Hill (USA). The powders underwent a ball-milling process for $10 \mathrm{~h}$ and were then pressed into cylindrical discs at $30 \mathrm{MPa}$. The fabrication process was followed by a modified liquid exfoliation method [39]. These green products were heated to $1,500^{\circ} \mathrm{C}$ for $2 \mathrm{~h}$ under inert atmosphere (Ar flow). The as-fabricated $\mathrm{Ti}_{3} \mathrm{AlC}_{2}$ precursor was crushed into powder. Then, $5 \mathrm{~g}$ powders was immersed in $60 \mathrm{~mL}$ of $\sim 40 \% \mathrm{HF}$ aqueous solution (Shanghai Macklin Biochemical Co., Ltd, China) for three days at room temperature (RT). After washing and centrifugation with oxygen-free water, the precipitate was collected and dispersed into $50 \mathrm{~mL}$ TPAOH aqueous solution (tetrapropylammonium hydroxide $25 \mathrm{wt} \%$ aqueous solution, J\&K Scientific Co., Ltd., Beijing, China) for three days under stirring at RT. Subsequently, the assynthesized $\mathrm{Ti}_{3} \mathrm{C}_{2}$ was collected and washed for three times with oxygen-free water to remove the residual TPAOH.

\section{Characterization}

X-ray diffraction (XRD) was performed by a Rigaku D/MAX-2200 PC XRD system with $\mathrm{Cu} \mathrm{Ka}$ radiation $(\lambda=1.54 \AA)$ at $40 \mathrm{~mA}$ and $40 \mathrm{kV}$. Transmission electron microscopy (TEM) images were obtained by a JEM-2100F electron microscope under $200 \mathrm{kV}$. Scanning electron microscopy (SEM) was conducted on a field-emission Magellan 400 microscope (FEI Company). X-ray photoelectron spectroscopy (XPS) was performed on ESCAlab250 (Thermal Scientific). Atomic force microscopy (AFM) analysis was acquired by Veeco DI Nanoscope Multi Mode V system. The concentration of sample was detected by inductively coupled plasma atomic emission spectroscopy (ICP-AES, Agilent Technologies).

\section{Electrochemical measurements}

Cyclic voltammetry $(\mathrm{CV})$ data were obtained by a standard three-electrode method on a CHI-760E electrochemical workstation ( $\mathrm{CH}$ Instrument, Inc.). Glassy carbon (GC) disc of $6 \mathrm{~mm}$ in diameter served as a substrate for the catalyst. Catalyst ink was prepared by mixing $10 \mathrm{mg}$ catalyst, $1 \mathrm{~mL}$ water and $1 \mathrm{~mL}$ ethanol. After $30 \mathrm{~min}$ in a ultrasonic bath, $20 \mu \mathrm{L}$ catalyst ink was transferred onto the GC electrode, yielding a catalyst loading level of $0.35 \mathrm{mg} \mathrm{cm}^{-2}$. An $\mathrm{Ag} / \mathrm{AgCl}\left(3 \mathrm{~mol} \mathrm{~L}^{-1}\right.$ $\mathrm{KCl}$ ) and graphite pod served as the counter and reference electrodes, respectively. $0.1 \mathrm{~mol} \mathrm{~L}^{-1} \mathrm{KOH}$ solution was used as the electrolyte for all electrochemical measurements. The CV curves were obtained by cycling scans at $50 \mathrm{mV} \mathrm{s}^{-1}$ after purging with nitrogen or oxygen for at least $15 \mathrm{~min}$ at ambient temperature. Alumina slurry with particle diameter of $1.0,0.3$, and $0.05 \mu \mathrm{m}$ was used in sequence to polish the GC electrode before the electrochemical characterization. Rotating disk electrode (RDE) and rotating ring-disk electrode (RRDE) measurements were performed on Pine Research Instruments in $\mathrm{O}_{2}$-saturated $0.1 \mathrm{~mol} \mathrm{~L}^{-1} \mathrm{KOH}$ solution at rotating rates varying from 400 to $2,025 \mathrm{rpm}$ with a scan rate of 
$5 \mathrm{mV} \mathrm{s}^{-1}$. Linear-sweep voltammetry (LSV) was performed on an RDE with diameter of $3 \mathrm{~mm}$. For RRDE, the disk electrode was scanned at a rate of $5 \mathrm{mV} \mathrm{s}^{-1}$, and the ring potential was constant at $0.6 \mathrm{~V} v s . \mathrm{Ag} / \mathrm{AgCl}$. The $\mathrm{HO}_{2}^{-}$percentage and the electron transfer number $(n)$ were calculated by Equations (1) and (2), respectively:

$$
\begin{gathered}
\%\left(\mathrm{HO}_{2}^{-}\right)=200 \times \frac{I_{\mathrm{r}} / N}{I_{\mathrm{d}}+I_{\mathrm{r}} / N}, \\
n=4 \times \frac{I_{\mathrm{d}}}{I_{\mathrm{d}}+I_{\mathrm{r}} / N},
\end{gathered}
$$

where $I_{\mathrm{d}}$ is the disk current, $I_{\mathrm{r}}$ is the ring current, and $N$ is the current collection efficiency of the Pt ring; $N$ was determined to be 0.40 from the reduction of $\mathrm{K}_{3}\left[\mathrm{Fe}(\mathrm{CN})_{6}\right]$.

\section{RESULTS AND DISCUSSION}

$\mathrm{Ti}_{3} \mathrm{AlC}_{2}$ phase ceramics were etched by $40 \% \mathrm{HF}$ aqueous solution to remove the $\mathrm{Al}$ layer. Then, in order to obtain the highly dispersible ultrathin $\mathrm{Ti}_{3} \mathrm{C}_{2}$ nanosheets, the etched multilayer $\mathrm{Ti}_{3} \mathrm{C}_{2}$ powder (noted as $\mathrm{ML} \mathrm{Ti}_{3} \mathrm{C}_{2}$ ) was intercalated with $\mathrm{TPAOH}$ in water to substantially reduce the planar dimensions (Fig. 1a). The as-prepared ultrathin $\mathrm{Ti}_{3} \mathrm{C}_{2}$ nanosheets (noted as $\mathrm{SL} \mathrm{Ti}_{3} \mathrm{C}_{2}$ ) with nanoscale lateral size and atom-scale thickness enable the ORR process with high efficiency.

The $\mathrm{Ti}_{3} \mathrm{AlC}_{2}$ MAX phase was synthesized by a solidstate reaction (Fig. 1b). SEM images show that $\mathrm{Ti}_{3} \mathrm{AlC}_{2}$ MAX phase is lamellar (Fig. 1c, d). Both high-resolution TEM (HRTEM) image and selected-area electron diffraction (SAED) pattern exhibit $\mathrm{Ti}_{3} \mathrm{AlC}_{2}$ with a hexagonal $\left(\mathrm{PG}_{3} / \mathrm{mmc}\right)$ structure (Fig. 1e and inset). SEM images reveal the microstructure of HF-treated $\mathrm{Ti}_{3} \mathrm{C}_{2}$ powder (Fig. 1f) exhibiting well-stacked, uniform planar morphology (Fig. 1g, h). HRTEM image shows the hexagonal crystalline lattice of multilayer $\mathrm{Ti}_{3} \mathrm{C}_{2}$ nanosheets, and the corresponding SAED pattern indicates that the basal hexagonal symmetry of the parent MAX phase has been well-retained after HF etching (Fig. 1i and inset). After further intercalation of TPAOH, bright-field TEM images reveals ultrathin, electron-transparent and free-standing flakes of exfoliated $\mathrm{Ti}_{3} \mathrm{C}_{2}$ nanosheets (Fig. 1k, 1), which exhibit the typical planar morphology with an average lateral size of $\sim 150 \mathrm{~nm}$. The Fourier transform pattern exhibits that $\mathrm{Ti}_{3} \mathrm{C}_{2}$ nanosheets have well-preserved defined hexagonal structure, and the corresponding original SAED further confirms the unchanged hexagonal symmetry structure (Fig. $1 \mathrm{~m}$ and inset). Digital photographs of free-standing $\mathrm{Ti}_{3} \mathrm{C}_{2}$ nanosheets show a typical Tyndall effect, featuring their excellent dispersity and hydrophilicity (Fig. 1j). The electron energy loss spectrum (EELS) confirms the existence of $\mathrm{Ti}, \mathrm{C}, \mathrm{O}$ and the absence of $\mathrm{Al}$, indicating its removal from the structure (Fig. S1).

AFM image confirms the formation of free-standing SL $\mathrm{Ti}_{3} \mathrm{C}_{2}$ (Fig. 2a, c). The statistical thickness distribution of as-fabricated $\mathrm{Ti}_{3} \mathrm{C}_{2}$ measured by AFM exhibits the sheet heights of about $0.5-2.0 \mathrm{~nm}$, which matches well with the dimension of a single-layer or double-layer $\mathrm{Ti}_{3} \mathrm{C}_{2}$
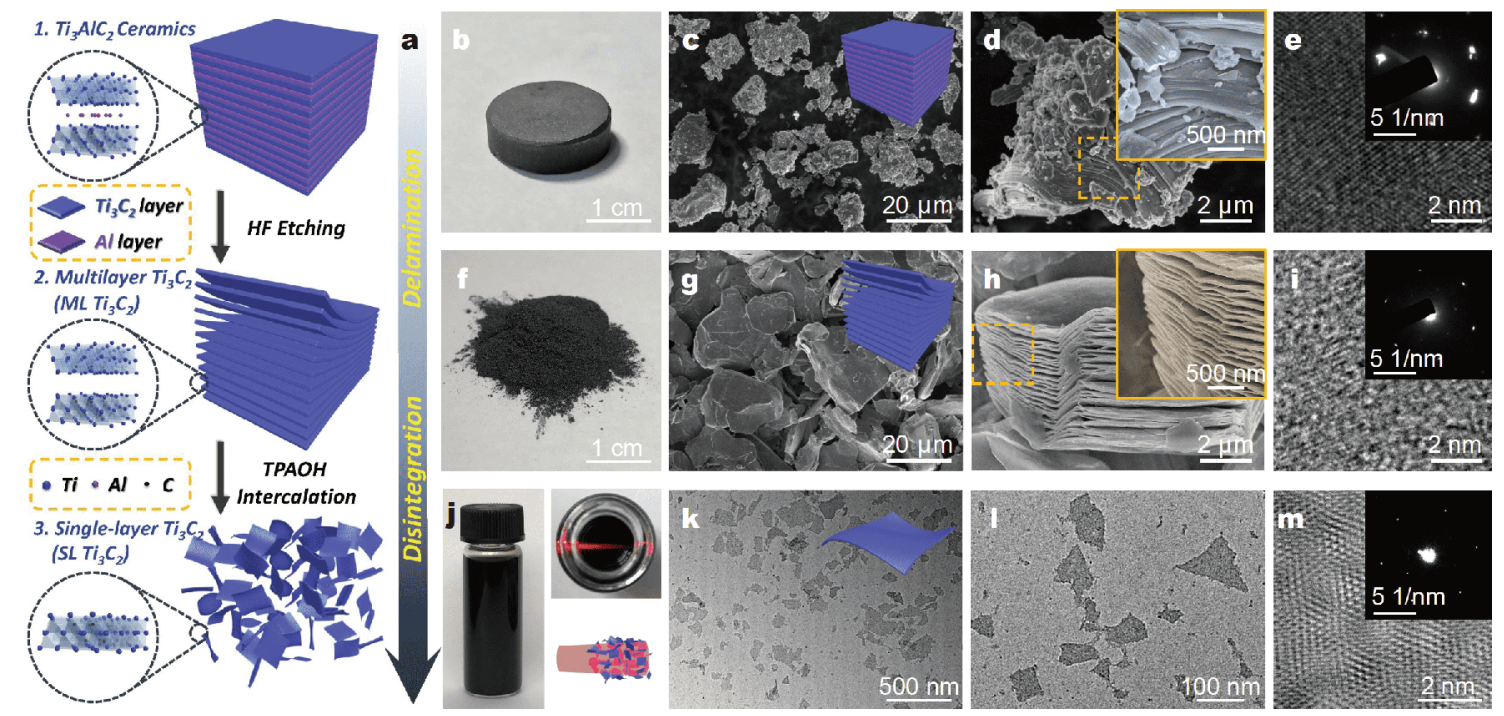

Figure 1 (a) Schematic diagram of ultrathin $\mathrm{Ti}_{3} \mathrm{C}_{2}$ nanosheets fabrication process, including HF etching (delamination) and TPAOH intercalation (disintegration). (b) Digital photographs, (c, d) SEM images, (e) HRTEM image (inset shows the corresponding SAED pattern) of Ti $\mathrm{AlC}_{2}$ ceramics (MAX phase). (f) Digital photographs, (g, h) SEM images, (i) HRTEM image (inset shows the corresponding SAED pattern) of ML Ti ${ }_{3} \mathrm{C}_{2}$. (j) Digital photographs, $(\mathrm{k}, \mathrm{l})$ TEM images, (m) HRTEM image (inset shows the corresponding SAED pattern) of SL $\mathrm{Ti}_{3} \mathrm{C}_{2}$. 

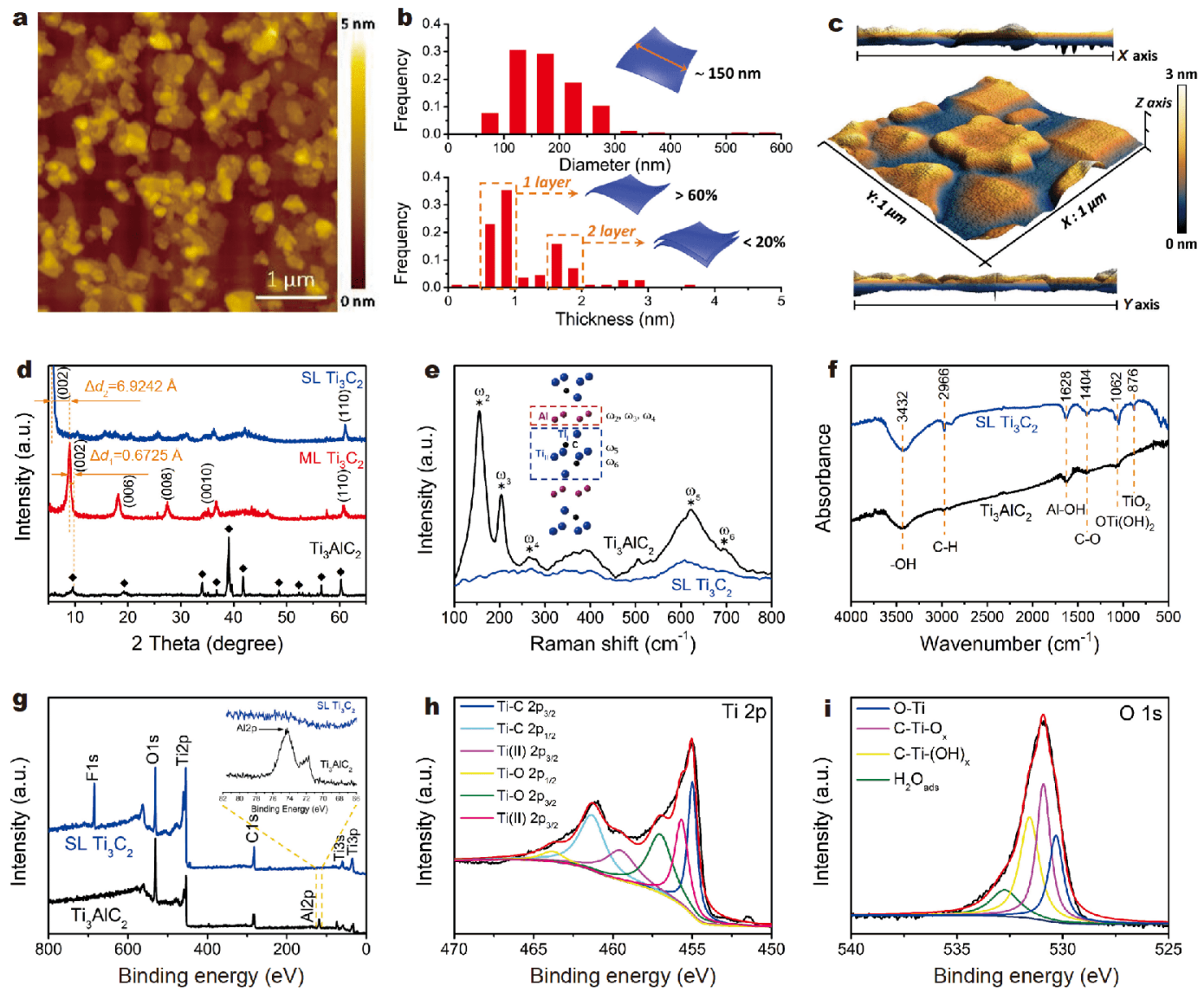

Figure 2 (a) Typical AFM image of $\mathrm{Ti}_{3} \mathrm{C}_{2}$ nanosheets. (b) Lateral size and thickness distribution analysis of $\mathrm{Ti}_{3} \mathrm{C}_{2}$ nanosheets. (c) AFM $3 \mathrm{D}$ view of a selected area in (a). (d) XRD patterns of $\mathrm{Ti}_{3} \mathrm{AlC}_{2}$ bulks and $\mathrm{Ti}_{3} \mathrm{C}_{2}$ nanosheets. (e) Raman spectra of $\mathrm{Ti}_{3} \mathrm{AlC}_{2}$ bulks and $\mathrm{Ti}_{3} \mathrm{C}_{2}$ nanosheets. (f) FTIR spectra of $\mathrm{Ti}_{3} \mathrm{AlC}_{2}$ bulks and $\mathrm{Ti}_{3} \mathrm{C}_{2}$ nanosheets. (g) XPS spectra of $\mathrm{Ti}_{3} \mathrm{AlC}_{2}$ bulks and $\mathrm{Ti}_{3} \mathrm{C}_{2}$ nanosheets in the region containing all possible elements. (h) XPS spectra of $\mathrm{Ti}_{3} \mathrm{C}_{2}$ nanosheets in $\mathrm{Ti} 2 \mathrm{p}$ region. (i) XPS spectra of $\mathrm{Ti}_{3} \mathrm{C}_{2}$ nanosheets in $\mathrm{O}$ 1s region.

nanosheets in thickness. The lateral size of $\sim 150 \mathrm{~nm}$ is consistent with the TEM images (Fig. 2b). XRD pattern demonstrates the successful fabrication of $\mathrm{Ti}_{3} \mathrm{AlC}_{2} \mathrm{MAX}$ phase (Fig. 2d, black curve). The peak intensities originating from the parent $\mathrm{Ti}_{3} \mathrm{AlC}_{2}$ bulk sequentially decreased after $\mathrm{HF}$ etching and $\mathrm{TPAOH}$ intercalation. Especially, the (002) peaks were broadened significantly and downshifted to $8.69^{\circ}$ for $\mathrm{ML} \mathrm{Ti}_{3} \mathrm{C}_{2}$ or $5.59^{\circ}$ for $\mathrm{SL}$ $\mathrm{Ti}_{3} \mathrm{C}_{2}$. The newly emerging low-angle (002) peaks, typical for MXenes, confirm that the entire sample has converted to $\mathrm{SL} \mathrm{Ti}_{3} \mathrm{C}_{2}$ MXenes [42,43]. Additionally, the disappearance of the most intense peak of $\mathrm{Ti}_{3} \mathrm{AlC}_{2}$ phase at $2 \theta$ around $39^{\circ}$ is due to the exfoliation. In Fig. 2e of Raman spectra of $\mathrm{Ti}_{3} \mathrm{AlC}_{2}$ and $\mathrm{Ti}_{3} \mathrm{C}_{2}$ nanosheets, disappearance of the vibration modes $\omega_{2}, \omega_{3}$ and $\omega_{4}$ after HF treatment implies the removal of Al layer or the exchange of $\mathrm{Al}$ atoms with other atoms. Mode $\omega_{5}$ has downshifted and weakened, while mode $\omega_{6}$ has been merged and suppressed, which indicates the well-preserved $\mathrm{Ti}_{3} \mathrm{C}_{2}$ layer and increased interlayer spacing of the MXene structure (Fig. S2).

$\mathrm{Ti}_{3} \mathrm{C}_{2}$ nanosheets were analyzed by energy-dispersive $\mathrm{X}$-ray spectroscopy (EDS) and XPS to probe the composition and surface terminations. EDS results confirm the presence of $\mathrm{Ti}, \mathrm{C}$ and $\mathrm{O}$ (Fig. S3). In general, carbon content estimated from the EDS spectra is inaccurate since carbon can be readily found as a contaminant. The high oxygen content measured by EDS could thus be due to either the water molecules intercalated between the MXene layers, which would be difficult to be removed completely, or the partial surface oxidation of $\mathrm{Ti}_{3} \mathrm{C}_{2}$ layers. XPS result of the $\mathrm{Ti}_{3} \mathrm{C}_{2}$ nanosheets shows the presence of $\mathrm{Ti}(\mathrm{IV}), \mathrm{TiC}_{x} \mathrm{O}_{y}$, and inherent $\mathrm{Ti}-\mathrm{C}$ bond, which indicates the formation of $\mathrm{TiO}_{2}$ or $\mathrm{Ti}_{3} \mathrm{C}_{2}(\mathrm{OH})_{2}$ (Fig. 2g-i).

To assess the ORR catalytic activity, our catalysts were 

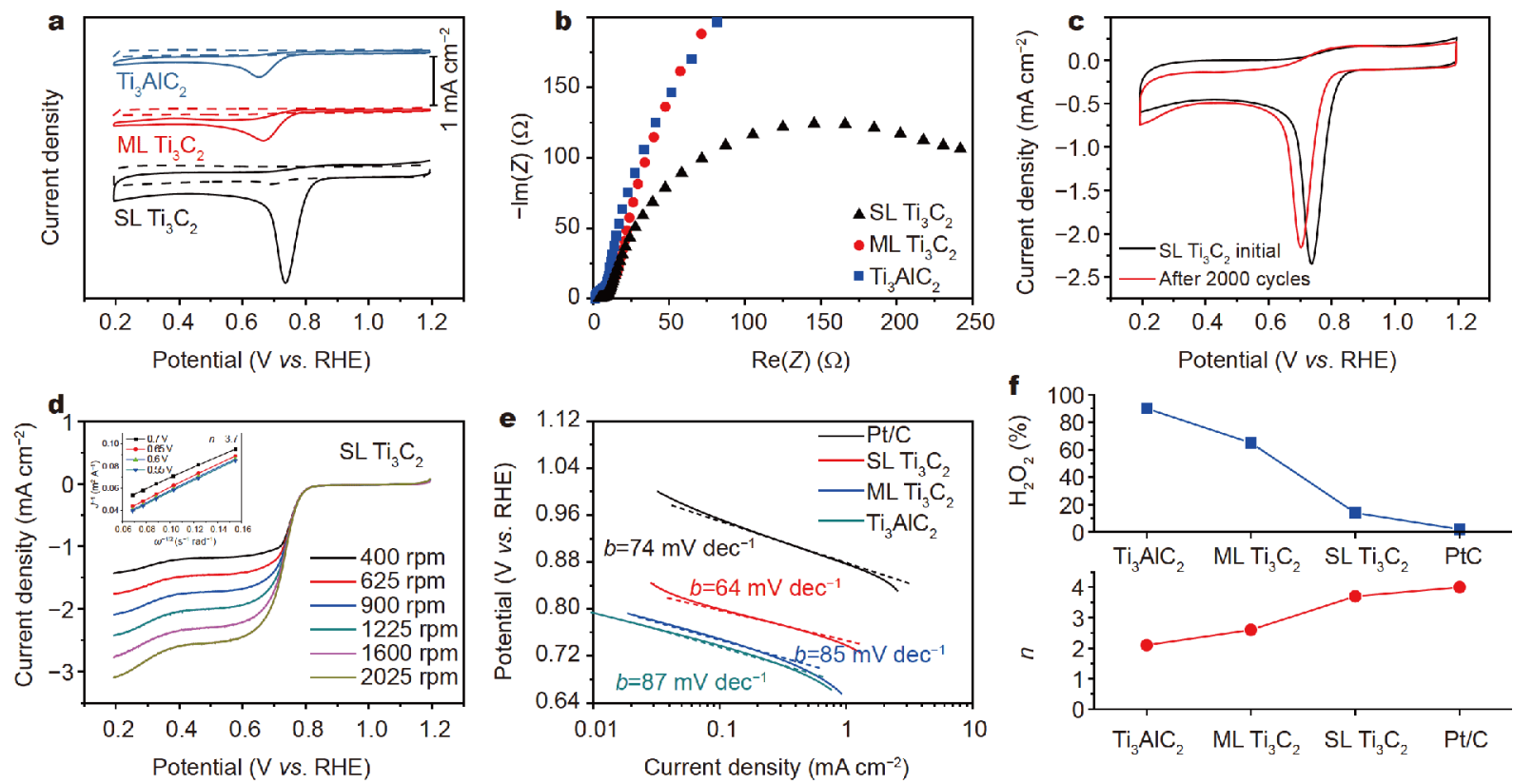

Figure 3 (a) CV curves of $\mathrm{Ti}_{3} \mathrm{AlC}_{2}, \mathrm{ML} \mathrm{Ti}_{3} \mathrm{C}_{2}$, and $\mathrm{SL} \mathrm{Ti}_{3} \mathrm{C}_{2}$ in $\mathrm{O}_{2}$-saturated (solid curves) and $\mathrm{N}_{2}$-saturated (dashed curves) $0.1 \mathrm{~mol} \mathrm{~L} \mathrm{LOH}^{-1} \mathrm{KO}$ at a scan rate of $100 \mathrm{mV} \mathrm{s}^{-1}$. (b) Nyquist plots of $\mathrm{Ti}_{3} \mathrm{AlC}_{2}, \mathrm{ML} \mathrm{Ti}_{3} \mathrm{C}_{2}$, and SL $\mathrm{Ti}_{3} \mathrm{C}_{2}$ recorded from EIS measurements in $\mathrm{O}_{2}$-saturated $0.1 \mathrm{~mol} \mathrm{~L} \mathrm{KOH}^{-1} \mathrm{Kat}^{-1}$ constant potential of $0.82 \mathrm{~V}$ (vs. RHE). (c) CV curves of the $\mathrm{SL} \mathrm{Ti}_{3} \mathrm{C}_{2}$ before and after cycled for 2,000 times in $0.1 \mathrm{~mol} \mathrm{~L}^{-1} \mathrm{KOH}$ saturated with $\mathrm{O}_{2}$ at a scan rate of $50 \mathrm{mV} \mathrm{s}^{-1}$ at $25^{\circ} \mathrm{C}$. (d) LSV profiles of SL $\mathrm{Ti}_{3} \mathrm{C}_{2}$ in $\mathrm{O}_{2}$-saturated $0.1 \mathrm{~mol} \mathrm{~L}^{-1} \mathrm{KOH}$ at varied rotation speeds but at a fixed scan rate of $5 \mathrm{mV} \mathrm{s}^{-1}$. Inset: the corresponding Koutecky-Levich plots for SL $\mathrm{Ti}_{3} \mathrm{C}_{2}$ at various potentials. (e) Tafel plots of the as-prepared samples $\left(\mathrm{Ti}_{3} \mathrm{AlC}_{2}, \mathrm{ML}\right.$ $\mathrm{Ti}_{3} \mathrm{C}_{2}$, and $\mathrm{SL} \mathrm{Ti}_{3} \mathrm{C}_{2}$ ) and commercial Pt/C catalyst derived by the mass-transport correction of corresponding RDE data. (f) Percentage of peroxide (blue curve) and the electron transfer number $(n)$ (Red curve) of $\mathrm{Ti}_{3} \mathrm{AlC}_{2}, \mathrm{ML} \mathrm{Ti}_{3} \mathrm{C}_{2}, \mathrm{SL} \mathrm{Ti}_{3} \mathrm{C}_{2}$ and $\mathrm{Pt} / \mathrm{C}$ at various potentials.

first loaded (with the same mass) onto glassy carbon electrodes. The ORR activities of $\mathrm{Ti}_{3} \mathrm{C}_{2}$ MXene catalysts were investigated in alkaline solution for RDE and RRDE measurements (Fig. 3). These results were compared with those of a commercial Pt/C catalyst. The ORR activity of the as-prepared $\mathrm{Ti}_{3} \mathrm{AlC}_{2}, \mathrm{ML} \mathrm{Ti}_{3} \mathrm{C}_{2}$ and $\mathrm{SL} \mathrm{Ti}_{3} \mathrm{C}_{2}$ was assessed by $\mathrm{CV}$ in $\mathrm{O}_{2}$ or $\mathrm{N}_{2}$-saturated $0.1 \mathrm{~mol} \mathrm{~L}^{-1} \mathrm{KOH}$ solution (Fig. S4). All the catalysts exhibit oxygen reduction activity in $\mathrm{O}_{2}$-saturated electrolyte, but no redox peaks could be found in the quasi-rectangular voltammograms of $\mathrm{N}_{2}$-saturated electrolyte. Remarkably, the $\mathrm{SL} \mathrm{Ti}_{3} \mathrm{C}_{2}$ shows a much more positive ORR onset potential, $\sim 0.85 \mathrm{~V}$ relative to the reversible hydrogen electrode (RHE), and higher peak current density than $\mathrm{Ti}_{3} \mathrm{AlC}_{2}$ and $\mathrm{ML} \mathrm{Ti}_{3} \mathrm{C}_{2}$ (Fig. 3a). Electrochemical impedance spectroscopy (EIS) was employed to investigate the charge transfer resistance at the electrode surface. In a typical Nyquist plot, the semicircle portion corresponds to the charge transfer resistance $\left(R_{\mathrm{ct}}\right)$. The lowest $R_{\mathrm{ct}}$ of SL $\mathrm{Ti}_{3} \mathrm{C}_{2}$ (Fig. 3b) indicates that it possesses the highest conductivity, which facilitates remarkable enhancement of ORR activity. The limit current density of $\mathrm{SL}_{\mathrm{Ti}_{3} \mathrm{C}_{2}}$ increases with scan rates (Fig. S5), indicating a diffusion-controlled process [44]. Moreover, a stable oxygen reduction current density of $2.3 \mathrm{~mA} \mathrm{~cm}^{-2}$ can be

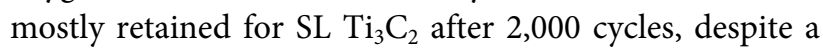
slight decline in comparison with the initial $\mathrm{CV}$ cycle (Fig. 3c).

We employed RDE measurements to evaluate the ORR kinetics of SL $\mathrm{Ti}_{3} \mathrm{C}_{2}$ in $0.1 \mathrm{~mol} \mathrm{~L}{ }^{-1} \mathrm{KOH}$ (Fig. 3d). The linearity of the Koutecky-Levich plots and nearly parallel fitting lines suggest the first-order reaction kinetics toward the oxygen-dissolved concentration and similar $n$ for ORR at varied potentials (Fig. 3d, inset) [45]. The $n$ was measured to be $\sim 3.7$ at $0.55-0.70 \mathrm{~V}$, depicting that SL $\mathrm{Ti}_{3} \mathrm{C}_{2}$ favors a four-electron (4e) pathway of oxygen reduction process, similar to the high-quality commercial

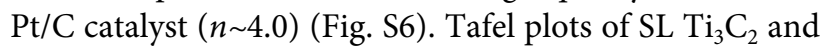
commercial $\mathrm{Pt} / \mathrm{C}$ derived by the mass-transport correction of corresponding LSV data were used to further evaluate the ORR activity of $\mathrm{Ti}_{3} \mathrm{C}_{2}$ MXene (Fig. 3e). The $\mathrm{SL} \mathrm{Ti}_{3} \mathrm{C}_{2}$ has a Tafel slope of $64 \mathrm{mV} \mathrm{dec}^{-1}$ in $0.1 \mathrm{~mol} \mathrm{~L}^{-1}$ $\mathrm{KOH}$, which is much lower than that of $\mathrm{Ti}_{3} \mathrm{AlC}_{2}$ and $\mathrm{ML}$ $\mathrm{Ti}_{3} \mathrm{C}_{2}$, but close to that of the commercial $\mathrm{Pt} / \mathrm{C}$ as $74 \mathrm{mV} \mathrm{dec}^{-1}$ [46], suggesting that $\mathrm{SL} \mathrm{Ti}_{3} \mathrm{C}_{2}$ features a favorable kinetics for ORR. 

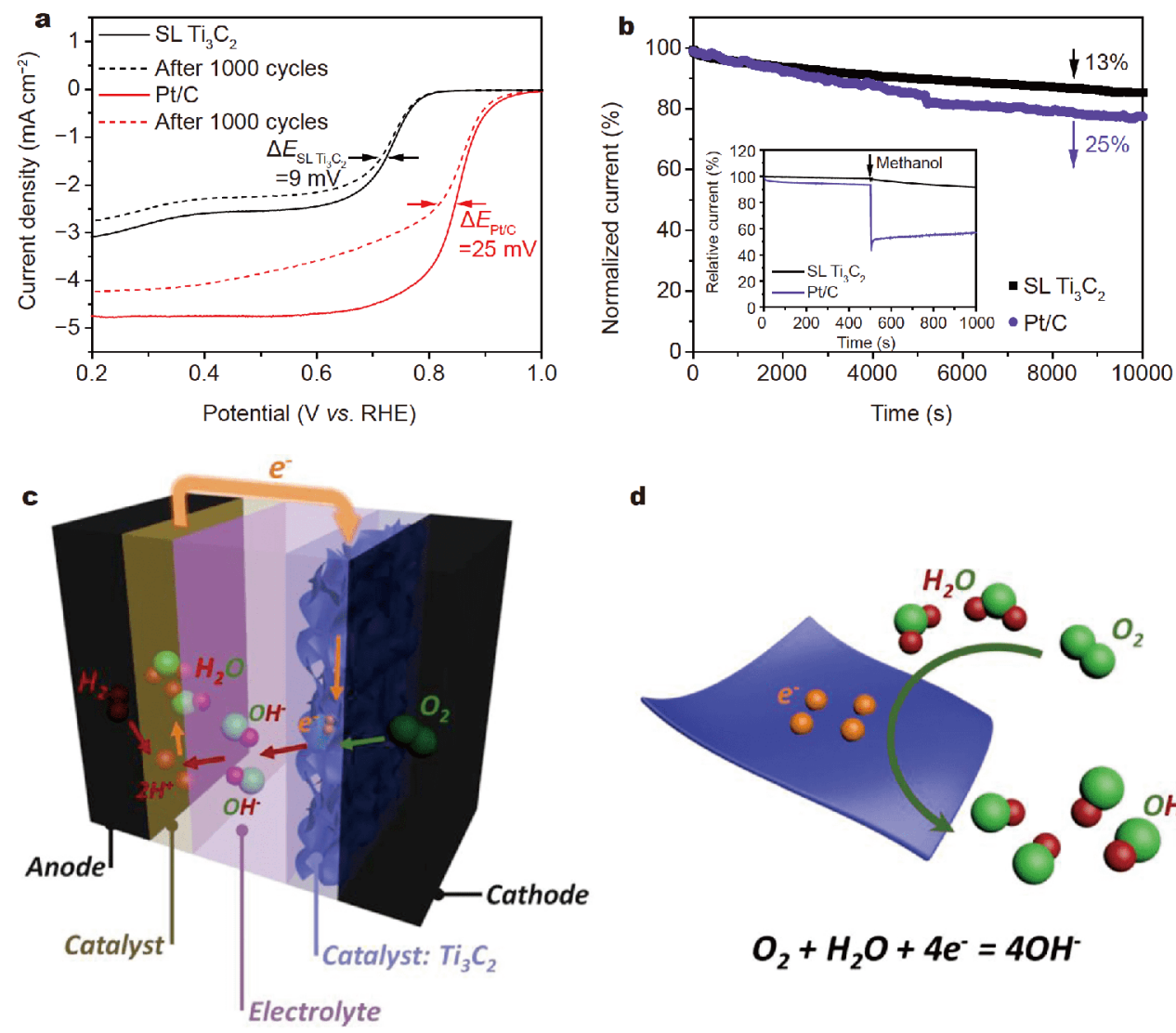

d

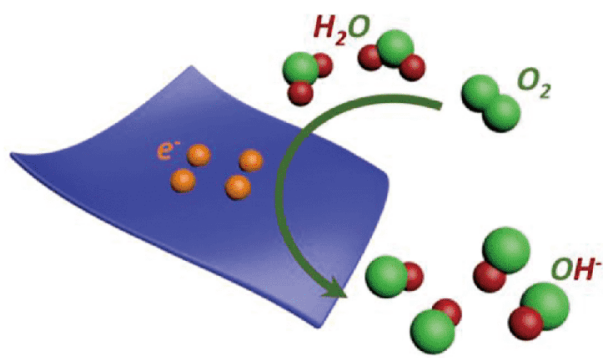

$\mathrm{O}_{2}+\mathrm{H}_{2} \mathrm{O}+4 e^{-}=4 \mathrm{OH}^{-}$

Figure 4 ORR stability and mechanism of $2 \mathrm{D} \mathrm{Ti}_{3} \mathrm{C}_{2}$. (a) LSV curves before and after accelerated degradation test conducted in $0.1 \mathrm{~mol} \mathrm{~L} \mathrm{LOH}^{-1} \mathrm{Ka}$ scan rate of $5 \mathrm{~m} \mathrm{~V} \mathrm{~s}^{-1}$ for the $\mathrm{SL} \mathrm{Ti}_{3} \mathrm{C}_{2}$ and Pt/C. (b) Durability evaluation from the current-time $(i-t)$ chronoamperometric responses of the SL Ti ${ }_{3} \mathrm{C}_{2}$ and commercial Pt/C catalysts in $\mathrm{O}_{2}$-saturated $0.1 \mathrm{~mol} \mathrm{~L}^{-1} \mathrm{KOH}$ solution at $0.82 \mathrm{~V}$ ( $v s$. RHE) and a rotation rate of $1,600 \mathrm{rpm}$. Inset: $i$ - $t$ curves for the methanol-crossover effect. (c) The $\mathrm{OH}^{-}$derived from the oxygen reduction reaches the anode through the polymer membrane, and therein combines with $\mathrm{H}^{+}$to form water. (d) Schematic illustration of the oxygen reduction reaction on $\mathrm{SL} \mathrm{Ti}_{3} \mathrm{C}_{2}$ catalyst surface.

RRDE measurements of the $\mathrm{Ti}_{3} \mathrm{C}_{2}$ MXene catalyst recorded the formation of peroxide species $\left(\mathrm{H}_{2} \mathrm{O}_{2}\right)$ during the ORR process (Fig. 3f, top) [47]. The measured $\mathrm{H}_{2} \mathrm{O}_{2}$ yields are below $\sim 14 \%$ and $\sim 3 \%$ for $\mathrm{SL}_{\mathrm{Ti}_{3}} \mathrm{C}_{2}$ and $\mathrm{Pt} / \mathrm{C}$, respectively, over the potential range of $0.55-0.70 \mathrm{~V}$, giving $n \sim 3.7$ for $\mathrm{SL} \mathrm{Ti}_{3} \mathrm{C}_{2}$ (Fig. 3f, bottom), consistent with that calculated by the Koutecky-Levich plots based on $\mathrm{RDE}$ measurements, suggesting that the oxygen

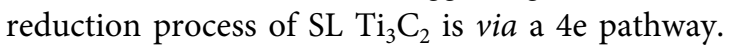

Some dominant factors such as catalytic activity, cost, and durability should be considered in choosing ORR catalysts for practical applications in fuel cells. As demonstrated above, the as-fabricated $\mathrm{SL} \mathrm{Ti}_{3} \mathrm{C}_{2}$ features desirable ORR activity with cost-effective production, and we further investigated its stability via the accelerated durability tests [48]. It can be found that the $E_{1 / 2}$ of SL $\mathrm{Ti}_{3} \mathrm{C}_{2}$ exhibits a slight negative shift by $9 \mathrm{mV}$ after 1,000 potential cycles between 0.4 and $1.0 \mathrm{~V}$ ( $v s$. RHE) in
$0.1 \mathrm{~mol} \mathrm{~L}^{-1} \mathrm{KOH}$ at $5 \mathrm{~m} \mathrm{~V} \mathrm{~s}^{-1}$, while the $\mathrm{Pt} / \mathrm{C}$ shows a $25 \mathrm{mV}$ reduction of its $E_{1 / 2}$ (Fig. 4a). Chronoamperometric measurement confirms the SL $\mathrm{Ti}_{3} \mathrm{C}_{2}$ has much higher stability than the commercial $\mathrm{Pt} / \mathrm{C}$. In fact, after a continuous operation for $10,000 \mathrm{~s}$, the $\mathrm{Pt} / \mathrm{C}$ showed a $25 \%$ current decay, but the $\mathrm{SL} \mathrm{Ti}_{3} \mathrm{C}_{2}$ retained $\sim 87 \%$ of the initial current, which suggests that our catalyst has higher durability than the $\mathrm{Pt} / \mathrm{C}$ for the ORR process in alkaline medium (Fig. 4b). Furthermore, the methanol-crossover effect was evaluated for the $\mathrm{SL} \mathrm{Ti}_{3} \mathrm{C}_{2}$ and the commercial $\mathrm{Pt} / \mathrm{C}$ in $\mathrm{O}_{2}$-saturated $0.1 \mathrm{~mol} \mathrm{~L}^{-1} \mathrm{KOH}$ solution with $5 \%$ (in volume) methanol. It is shown that the introduction of methanol only results in a slight deterioration of ORR

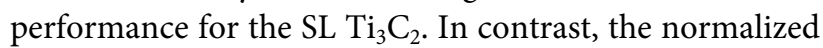
current of $\mathrm{Pt} / \mathrm{C}$ dropped dramatically when methanol was added into the electrolyte (Fig. $4 \mathrm{~b}$ inset), featuring an evident applicability of the as-prepared $\mathrm{SL} \mathrm{Ti}_{3} \mathrm{C}_{2}$ in direct methanol fuel cells. 
Generally, oxygen adsorption, electron transfer and active sites are the important parameters of electrocatalysts. Therefore, the reason for the high electroactivity and stability of $2 \mathrm{D} \mathrm{Ti}_{3} \mathrm{C}_{2}$ towards ORR is proposed as below. Firstly, a large surface area, which results from the ultrathin uniform 2D structure, is in favor of the oxygen adsorption. Secondly, the high conductivity of $2 \mathrm{D} \mathrm{Ti}_{3} \mathrm{C}_{2}$, which has been confirmed by the EIS results, is in favor of the electron transfer during the oxygen reduction processes. Last but most importantly, there are large amounts of $-\mathrm{F}$ dangling bonds on the surface of $2 \mathrm{D}$ structures. The large electronegativity of $-\mathrm{F}$ dangling bonds takes effect on the electronic structure of $2 \mathrm{D} \mathrm{Ti}_{3} \mathrm{C}_{2}$, and serve as the active sites of ORR processes. [49].

\section{CONCLUSIONS}

In summary, a robust, noble metal-free nanocatalyst, freestanding $2 \mathrm{D} \mathrm{Ti}_{3} \mathrm{C}_{2}$ MXene nanosheets derived from the bulk rigid ceramics (MAX phase), was fabricated by a liquid exfoliation process combining HF etching (delamination) and TPAOH intercalation (disintegration). The $\mathrm{Ti}_{3} \mathrm{C}_{2}$ MXene-based catalyst exhibited desirable ORR activity and stability in alkaline media. With a sandwich-like structure consisting of titanium atoms at the surface layer or terminals and carbon atoms at the inner layer, the catalyst is a perfect model system for understanding the ORR active sites of this kind of $2 \mathrm{D}$ layer-by-layer catalysts. This study gives a novel pathway to utilize $\mathrm{Ti}_{3} \mathrm{C}_{2}$ MXene-based catalyst with desirable ORR activity and stability in alkaline media, which demonstrates the potential of earth-abundant 2D MXenes for constructing high-performance and cost-effective electrocatalysts.

Received 12 September 2018; accepted 28 November 2018; published online 20 December 2018

1 Chen Z, Higgins D, Yu A, et al. A review on non-precious metal electrocatalysts for PEM fuel cells. Energy Environ Sci, 2011, 4: 3167

2 Jaouen F, Proietti E, Lefèvre M, et al. Recent advances in nonprecious metal catalysis for oxygen-reduction reaction in polymer electrolyte fuel cells. Energy Environ Sci, 2011, 4: 114-130

3 Gong K, Du F, Xia Z, et al. Nitrogen-doped carbon nanotube arrays with high electrocatalytic activity for oxygen reduction. Science, 2009, 323: 760-764

4 Wang S, Yu D, Dai L. Polyelectrolyte functionalized carbon nanotubes as efficient metal-free electrocatalysts for oxygen reduction. J Am Chem Soc, 2011, 133: 5182-5185

5 Yan D, Guo L, Xie C, et al. N, P-dual doped carbon with trace Co and rich edge sites as highly efficient electrocatalyst for oxygen reduction reaction. Sci China Mater, 2018, 61: 679-685

$6 \mathrm{Xu} \mathrm{D}, \mathrm{Mu}$ C, Wang B, et al. Fabrication of multifunctional carbon encapsulated $\mathrm{Ni@NiO} \mathrm{nanocomposites} \mathrm{for} \mathrm{oxygen} \mathrm{reduction,}$ oxygen evolution and lithium-ion battery anode materials. Sci China Mater, 2017, 60: 947-954

7 Wu S, Zhu Y, Huo Y, et al. Bimetallic organic frameworks derived $\mathrm{CuNi} /$ carbon nanocomposites as efficient electrocatalysts for oxygen reduction reaction. Sci China Mater, 2017, 60: 654-663

8 Zeng L, Cui X, Shi J. A facile strategy for ultrasmall Pt NPs being partially-embedded in $\mathrm{N}$-doped carbon nanosheet structure for efficient electrocatalysis. Sci China Mater, 2018, 61: 1557-1566

9 Wang Y, Tao L, Xiao Z, et al. 3D carbon electrocatalysts in situ constructed by defect-rich nanosheets and polyhedrons from $\mathrm{NaCl}$-sealed zeolitic imidazolate frameworks. Adv Funct Mater, 2018, 28: 1705356

10 Dou S, Tao L, Wang R, et al. Plasma-assisted synthesis and surface modification of electrode materials for renewable energy. Adv Mater, 2018, 30: 1705850

11 Gao G, O'Mullane AP, Du A. 2D MXenes: A new family of promising catalysts for the hydrogen evolution reaction. ACS Catal, 2017, 7: 494-500

12 Guo Z, Zhou J, Zhu L, et al. MXene: a promising photocatalyst for water splitting. J Mater Chem A, 2016, 4: 11446-11452

13 Ma TY, Cao JL, Jaroniec M, et al. Interacting carbon nitride and titanium carbide nanosheets for high-performance oxygen evolution. Angew Chem Int Ed, 2016, 55: 1138-1142

14 Pan H. Ultra-high electrochemical catalytic activity of MXenes. Sci Rep, 2016, 6: 32531

15 Seh ZW, Fredrickson KD, Anasori B, et al. Two-dimensional molybdenum carbide (MXene) as an efficient electrocatalyst for hydrogen evolution. ACS Energy Lett, 2016, 1: 589-594

16 Xie X, Chen S, Ding W, et al. An extraordinarily stable catalyst: Pt $\mathrm{NPs}$ supported on two-dimensional $\mathrm{Ti}_{3} \mathrm{C}_{2} \mathrm{X}_{2} \quad(\mathrm{X}=\mathrm{OH}, \quad \mathrm{F})$ nanosheets for oxygen reduction reaction. Chem Commun, 2013, 49: 10112-10114

17 Peng N, Hu D, Zeng J, et al. Superabsorbent cellulose-clay nanocomposite hydrogels for highly efficient removal of dye in water. ACS Sustain Chem Eng, 2016, 4: 7217-7224

18 Novoselov KS, Geim AK, Morozov SV, et al. Electric field effect in atomically thin carbon films. Science, 2004, 306: 666-669

19 Nicolosi V, Chhowalla M, Kanatzidis MG, et al. Liquid exfoliation of layered materials. Science, 2013, 340: 1226419

20 Tan C, Cao X, Wu XJ, et al. Recent advances in ultrathin twodimensional nanomaterials. Chem Rev, 2017, 117: 6225-6331

21 Chen Z, Wang Z, Ren J, et al. Enzyme mimicry for combating bacteria and biofilms. Acc Chem Res, 2018, 51: 789-799

22 Chen Y, Yang K, Jiang B, et al. Emerging two-dimensional nanomaterials for electrochemical hydrogen evolution. J Mater Chem A, 2017, 5: 8187-8208

23 Tao H, Gao Y, Talreja N, et al. Two-dimensional nanosheets for electrocatalysis in energy generation and conversion. J Mater Chem A, 2017, 5: 7257-7284

24 Li K, Jiao T, Xing R, et al. Fabrication of tunable hierarchical MXene@AuNPs nanocomposites constructed by self-reduction reactions with enhanced catalytic performances. Sci China Mater, 2018, 61: 728-736

25 Naguib M, Kurtoglu M, Presser V, et al. Two-dimensional nanocrystals produced by exfoliation of $\mathrm{Ti}_{3} \mathrm{AlC}_{2}$. Adv Mater, 2011, 23: 4248-4253

26 Anasori B, Lukatskaya MR, Gogotsi Y. 2D metal carbides and nitrides (MXenes) for energy storage. Nat Rev Mater, 2017, 2: 16098 
27 Liang X, Garsuch A, Nazar LF. Sulfur cathodes based on conductive MXene nanosheets for high-performance lithiumsulfur batteries. Angew Chem Int Ed, 2015, 54: 3907-3911

28 Mashtalir O, Lukatskaya MR, Zhao MQ, et al. Amine-assisted delamination of $\mathrm{Nb}_{2} \mathrm{C}$ MXene for Li-ion energy storage devices. Adv Mater, 2015, 27: 3501-3506

29 Zhao MQ, Xie X, Ren CE, et al. Hollow MXene spheres and 3D macroporous MXene frameworks for Na-ion storage. Adv Mater, 2017, 29: 1702410

30 Ghidiu M, Lukatskaya MR, Zhao MQ, et al. Conductive twodimensional titanium carbide 'clay' with high volumetric capacitance. Nature, 2014, 3: 78-81

31 Lukatskaya MR, Mashtalir O, Ren CE, et al. Cation intercalation and high volumetric capacitance of two-dimensional titanium carbide. Science, 2013, 341: 1502-1505

32 Zhang CJ, Anasori B, Seral-Ascaso A, et al. Transparent, flexible, and conductive 2D titanium carbide (MXene) films with high volumetric capacitance. Adv Mater, 2017, 29: 1702678

33 Ding L, Wei Y, Wang Y, et al. A two-dimensional lamellar membrane: MXene nanosheet stacks. Angew Chem Int Ed, 2017, 56: $1825-1829$

34 Kim SJ, Koh HJ, Ren CE, et al. Metallic $\mathrm{Ti}_{3} \mathrm{C}_{2} \mathrm{~T}_{x}$ MXene gas sensors with ultrahigh signal-to-noise ratio. ACS Nano, 2018, 12: 986-993

35 Li N, Chen X, Ong WJ, et al. Understanding of electrochemical mechanisms for $\mathrm{CO}_{2}$ capture and conversion into hydrocarbon fuels in transition-metal carbides (MXenes). ACS Nano, 2017, 11: $10825-10833$

36 Liu J, Zhang HB, Sun R, et al. Hydrophobic, flexible, and lightweight MXene foams for high-performance electromagneticinterference shielding. Adv Mater, 2017, 29: 1702367

37 Shahzad F, Alhabeb M, Hatter CB, et al. Electromagnetic interference shielding with 2D transition metal carbides (MXenes). Science, 2016, 353: 1137-1140

38 Lin H, Gao S, Dai C, et al. A two-dimensional biodegradable niobium carbide (MXene) for photothermal tumor eradication in NIR-I and NIR-II biowindows. J Am Chem Soc, 2017, 139: 1623516247

39 Lin H, Wang X, Yu L, et al. Two-dimensional ultrathin MXene ceramic nanosheets for photothermal conversion. Nano Lett, 2017, 17: $384-391$

40 Lin H, Wang Y, Gao S, et al. Theranostic 2D tantalum carbide (MXene). Adv Mater, 2018, 30: 1703284

41 Lin $\mathrm{H}$, Chen $\mathrm{Y}$, Shi J. Insights into 2D MXenes for versatile biomedical applications: Current advances and challenges ahead. Adv Sci, 2018, 5: 1800518

42 Urbankowski P, Anasori B, Makaryan T, et al. Synthesis of twodimensional titanium nitride $\mathrm{Ti}_{4} \mathrm{~N}_{3}$ (MXene). Nanoscale, 2016, 8:
11385-11391

43 Zhou J, Zha X, Chen FY, et al. A two-dimensional zirconium carbide by selective etching of $\mathrm{Al}_{3} \mathrm{C}_{3}$ from nanolaminated $\mathrm{Zr}_{3} \mathrm{Al}_{3} \mathrm{C}_{5}$. Angew Chem, 2016, 128: 5092-5097

44 Wang Y, Zhang D, Peng W, et al. Electrocatalytic oxidation of methanol at $\mathrm{Ni}-\mathrm{Al}$ layered double hydroxide film modified electrode in alkaline medium. Electrochim Acta, 2011, 56: 57545758

45 Mayrhofer KJJ, Strmcnik D, Blizanac BB, et al. Measurement of oxygen reduction activities via the rotating disc electrode method: From Pt model surfaces to carbon-supported high surface area catalysts. Electrochim Acta, 2008, 53: 3181-3188

46 Ren G, Lu X, Li Y, et al. Porous core-shell $\mathrm{Fe}_{3} \mathrm{C}$ embedded Ndoped carbon nanofibers as an effective electrocatalysts for oxygen reduction reaction. ACS Appl Mater Interfaces, 2016, 8: 4118-4125

47 Paulus UA, Schmidt TJ, Gasteiger HA, et al. Oxygen reduction on a high-surface area $\mathrm{Pt} / \mathrm{Vulcan}$ carbon catalyst: a thin-film rotating ring-disk electrode study. J Electroanal Chem, 2001, 495: 134-145

$48 \mathrm{Wu}$ G, More KL, Johnston CM, et al. High-performance electrocatalysts for oxygen reduction derived from polyaniline, iron, and cobalt. Science, 2011, 332: 443-447

49 Sun X, Zhang Y, Song P, et al. Fluorine-doped carbon blacks: highly efficient metal-free electrocatalysts for oxygen reduction reaction. ACS Catal, 2013, 3: 1726-1729

Acknowledgements This work was financially supported by the National Key R\&D Program of China (2016YFA0203700), the National Natural Science Foundation of China (51702099, 51672303 and 51722211), the Program of Shanghai Academic Research Leader (18XD1404300), Young Elite Scientist Sponsorship Program by CAST (2015QNRC001), and Youth Innovation Promotion Association of the Chinese Academy of Sciences (2013169), Shanghai Sailing Program (17YF1403800), China Postdoctoral Science Foundation funded project (2017M611500), and the Opening Project of State Key Laboratory of High Performance Ceramics and Superfine Microstructure (SKL201702SIC).

Author contributions Shi J and Chen Y designed and engineered the samples; $\mathrm{Lu} \mathrm{X}$ conceived the post-fabrication tuning of random modes; Lin $\mathrm{H}$, Yao $\mathrm{H}$ and Chen $\mathrm{L}$ performed the experiments; Lin $\mathrm{H}$ wrote the paper with support from Chen L, Chen Y and Shi J. All authors contributed to the general discussion.

Conflict of interest The authors declare no conflict of interest.

Supplementary information Supplementary data are available in the online version of the paper. 

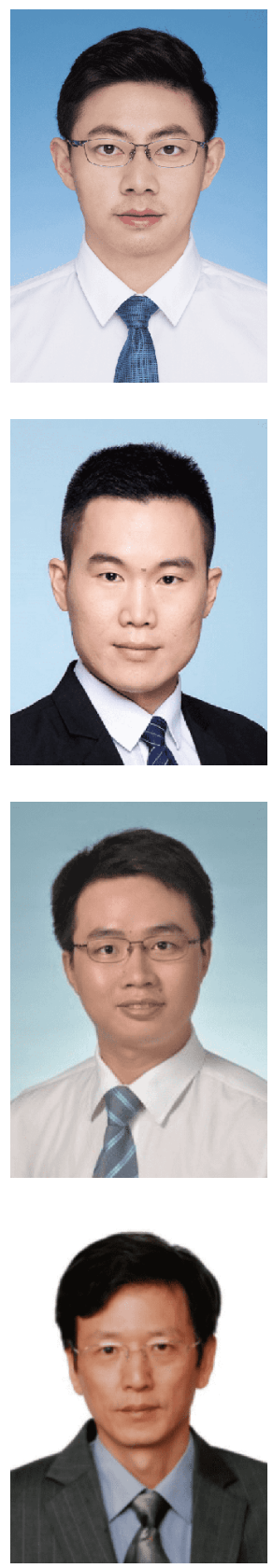

Han Lin received his Bachelor degree in materials science and engineering at Changchun University of Science and Technology (CUST) in 2014. He is currently a PhD candidate under the supervision of Prof. Yu Chen and Prof. Jianlin Shi in Shanghai Institute of Ceramics, Chinese Academy of Sciences (SICCAS). His research interest focuses on novel 2D nanomaterials in biomedical applications and nanocatalytic medicine (NCM).

Lisong Chen received his Bachelor degree in materials science and engineering at CUST in 2011 and his PhD degree under the supervision of Prof. Jianlin Shi from SICCAS in 2016. Since then, he has been a lecturer at the East China Normal University (ECNU). His research interest is electrocatalysts for renewable energy.

Yu Chen received his PhD degree at SICCAS. He is now a full professor in SICCAS. His research focuses on the design and synthesis of functional micro/nanoparticles including 0D, 2D biomaterials and 3D implants, and exploring their extensive biomedical applications in theranostic nanomedicine, catalytic nanomedicine, cardiac therapy and localized tumor therapy. He has published over 130 peer-reviewed papers with more than 7,800 citations (H-index: 45).

Jianlin Shi received his PhD degree from SICCAS. He is now a professor at SICCAS. His research areas include the synthesis of mesoporous materials and nanocomposites, and their catalytic, biomedical and optical applications. He has published over 450 scientific papers which have been cited more than 24,000 times by other scientists with an h-index of 84 (2017). He has been in charge of more than 30 important research projects and has gained a number of awards for his achievements.

\section{二维MXene相 $\mathrm{Ti}_{3} \mathrm{C}_{2}$ 高效氧还原电催化剂的制备和性能研究}

林翰 $^{1,3}$, 陈立松 ${ }^{2}$, 逯向雨 ${ }^{1,3}$, 姚鹤良 ${ }^{1}$, 陈雨 ${ }^{*}$, 施剑林 ${ }^{1,2^{*}}$

摘要 二维MXene材料, 由于具有良好的导电性和丰富的表面化学性质, 在电催化领域具有广泛的应用前景, 但在电催化氧还原领域鲜有 报道. 本文通过HF酸刻蚀和 TPAOH插层两步法, 用MAX陶瓷制备了具有二维层状结构的 MXene相 $\mathrm{Ti}_{3} \mathrm{C}_{2}$ 材料, 并将其用作氧还原电催化 剂. 制备的二维 $\mathrm{Ti}_{3} \mathrm{C}_{2}$ 材料厚度为 $0.5-2.0 \mathrm{~nm}$, 表明该材料的层数为 $1 \sim 2$ 层. CV、LSV、RRDE等测试表明, 二维 $\mathrm{Ti}_{3} \mathrm{C}_{2}$ 材料具有良好的 $\mathrm{ORR}$ 性 能和稳定性. 